\title{
Ultrasound-assisted adsorption of toxic dyes by cottonseed cake: artificial neural networks, regression models and response surface optimization
}

\author{
Buyukada M. ${ }^{*}$, Evrendilek F. and Karakaya N. \\ Department of Environmental Engineering, Abant Izzet Baysal University, Bolu, Turkey \\ Received: 01/01/2017, Accepted: 02/03/2017, Available online: 23/01/2018 \\ *to whom all correspondence should be addressed: e-mail: musabuyukada@hotmail.com
}

\begin{abstract}
In this study, dehydrated cottonseed cake as a low-cost and abundant byproduct in Turkey was utilized as an adsorbent for the decolorization of Reactive Blue 19 (RB19) and Reactive Yellow 145 (RY145) from aqueous solutions based on adsorption and ultrasound-assisted adsorption (UAA). Decolorization efficiency was optimized as a function of changes in process type, initial $\mathrm{pH}$ value, adsorbent concentration, temperature, reaction time, and initial dye concentrations of RY145 and RB19 based on response surface methodology (RSM) using Box-Behnken Design. The maximum decolorization efficiency of $99.9 \%$ for both RY145 and RB19 was obtained with ultrasound-assisted adsorption under the RSM-optimized conditions (with unity desirability) of 76.98 and 79.40 min reaction times, 233.20 and $254.29 \mathrm{mg} \mathrm{L}^{-1}$ initial dye concentrations, 1.37 and $1.44 \mathrm{~g} \mathrm{~L}^{-1}$ adsorbent concentrations, and 35.42 and $49.37{ }^{\circ} \mathrm{C}$, respectively. The best-fit multiple non-linear regression models of decolorization efficiency with the highest adjusted coefficients of determination $\left(R^{2}{ }_{\text {adj }}\right)$ explained $99.52 \%$ and $99.48 \%$ of variations through adsorption of RY145 and RB19 and $98.14 \%$ and $98.01 \%$ of variations through UAA of RY145 and RB19, respectively, while artificial neural networks accounted for $99.82 \%$.
\end{abstract}

Keywords: Adsorption; Data-driven modeling; Dehydrated cottonseed cake; Methylene blue; Ultrasound

\section{Introduction}

There exist thousands of commercially available dyes that are extensively used in such industries as pharmaceutics, leather, textile, paper printing, food, and cosmetics. However, these dyes when disposed also pose potential risks to public health and wildlife due to their such properties as low biodegradability, chemically complex structures, and toxicity (Sayan and Edecan, 2008; Tanyildizi, 2011). Thus, it is necessary for dyes to be removed from industrial wastewaters and effluents using innovative treatment techniques that are environmentally benign and economically feasible (Chen et al., 2015; Liu et al., 2015). Traditional treatment methods to achieve decolorization of wastewaters include chemical coagulation (Yang et al.,
2011), electrochemical treatment (Sahinkaya, 2013), and biological treatment (Onat et al., 2010). However, these methods are often ineffective in decolorizing of complex dyes (Hamdaoui et al., 2008). Thus, advanced oxidation processes have gained popularity in the removal of dyes (Zhou et al., 2013). In particular, the applications of sonochemical adsorption such as ultrasound-assisted adsorption (UAA) to wastewaters laden with dyes, aromatic compounds, and/or chlorinated hydrocarbons have been showed to be an effective removal process for a wide range of dye wastewaters and effluents owing to its efficiency, flexibility and economic feasibility. Such UAA treatments cause the formation, growth, and sudden collapse of acoustic cavitation-induced micro bubbles in an irradiated liquid, thus leading to localized but high temperatures up to $5000{ }^{\circ} \mathrm{C}$ and hundreds of bars of pressures (Guo et al., 2011). Movement of liquid induced by sonic waves; that is, the conversion of sound to kinetic energy increases the rate of mass transfer near the surface (Guo et al., 2011).

Although activated carbon is the most commonly used adsorbent for the removal of dyes, exploring alternative low-cost adsorbents with a potential comparable to activated carbon is highly desired (Yang et al., 2011). Examples of such low-cost adsorbents used in wastewater treatment include peanut hull (Gong et al., 2015; Buyukada, 2016), sol meal hull (Arami et al., 2006), caolbased bottom ash (Dincer et al., 2007), bentonite (Korkut et al., 2010), wheat bran (Ozer and Dursun, 2007), tomato waste (Yargic et al., 2015), dead pine needles (Hamdaoui et al., 2008), sludge and straw (Ren et al., 2016), and wood sawdust (Ofamaja and Ho, 2008). Another low cost and abundant agricultural by-product is cottonseed (Gossypium hirsutum) cake (CC) obtained when cottonseed oil is extracted from cotton crops. Given the world's and Turkey's annual cottonseed productions of 46 and 1.3 million tons in 2014, respectively, CC appears to have a great potential to be used as an adsorbent in wastewater treatment about which there exist limited experimental studies.

On the other hand, optimization designs and data-driven modeling are the integral part of such scientific studies of 
experimental nature as they are leveraged not only to maximize information extracted from data and minimize experimental random errors and runs but also to provide quantification, generalization, and thus, predictive power, respectively. Artificial neural networks (ANNs) and multiple non-linear regression (MNLR) models are the most commonly used tools to quantify and predict non-linear patterns and behaviors. Likewise, response surface methodology (RSM) is the most utilized design to determine optimum operating conditions to maximize or minimize non-linear response surfaces by taking into account second-degree interactions.

As is evident from the above introduction, the motivation behind the present study was threefold: increased efficacy of UAA, high potential of CC as an adsorbent, and empirical optimization and modeling as a leverage for a better understanding. The objective of this study was therefore to model and optimize decolorization efficiency for the two toxic dyes of Reactive Blue 19 (RB19) and Reactive Yellow 145 (RY145) through ANNs, MNLR models, and RSM optimization as a function of changes in process type (adsorption versus UAA), initial $\mathrm{pH}$, initial $\mathrm{CC}$ and dye concentrations, temperature, and reaction time.

\section{Materials and methods}

\subsection{Sampling and characterization of CC}

Cottonseed cake was utilized as an adsorbent and was supplied from a local textile plant in Adana, Turkey. After being washed with deionized water for the removal of soluble impurities, CC samples were obtained after being dried in an oven (DV452, Chanel, China) at $80{ }^{\circ} \mathrm{C}$ for $24 \mathrm{~h}$ for the removal of moisture. Immediately after being grinded using a ball mill (Mertest LB 220, England), the CC samples were sieved to obtain various fractions, using American Society for Testing and Materials (ASTM) standard sieves. The $\mathrm{CC}$ samples were stored in a $\mathrm{CaCl}_{2}$ desicator during the experimental study.

Specific surface areas of the CC samples were estimated from $\mathrm{N}_{2}$ adsorption isotherm data obtained at $77 \mathrm{~K}$ using a BET surface analyzer (Micnometrics, ASAP 2020). Prior to $\mathrm{N}_{2}$ adsorption isotherm experiments, CC was degassed at $131{ }^{\circ} \mathrm{C}$ (up to $1.33^{*} 10^{2}$ bar) for $6 \mathrm{~h}$. Pore size distribution of $\mathrm{CC}$ was also calculated from $\mathrm{N}_{2}$ adsorption isotherm, while particle size distribution of CC was obtained using a particle size analyzer (Malvern-Mastersizer 2000). Fourier Transform Infra Red (FTIR) spectrum of CC was obtained using a FTIR spectrometer (Matsson 1000 FTIR) based on the $\mathrm{KBr}$ pellet technique in the range of 400 to $4000 \mathrm{~cm}^{-1}$. $\mathrm{XRD}$ analysis was carried out to determine organic matter type of CC, using a diffractometer (Multiflex-DD2759N, Rikagu, Japan) with Cu Ka radiation ( $\lambda=1.568 \AA$ ). Zero point charge $\left(\mathrm{pH}_{\mathrm{zpc}}\right)$ of $\mathrm{CC}$ was measured using a zeta potential meter (Zetasizer, 3000HSA, Malvern, UK). The surface morphologies and elemental mapping of $\mathrm{CC}$ were analyzed using a SEM-EDX (JSM-6390V, Jeol, Japan). Chemical composition of CC was analyzed using an X-ray fluorescence spectrometer (XRF, Thermoscientific Lumina).

\subsection{Preparation of reactive dye solutions}

The commercial azo dyes with the following Color Index generic names of Reactive Yellow 145 (RY145, $\mathrm{C}_{28} \mathrm{H}_{20} \mathrm{ClN}_{9} \mathrm{O}_{16} \mathrm{~S}_{5} \mathrm{Na}_{4}$; molecular weight $=1026.26 \mathrm{~g} / \mathrm{mol}$; $\lambda_{\max }=420 \mathrm{~nm}$ ) and Reactive Blue 19 (RB19, molecular weight $=626.54 \mathrm{~g} / \mathrm{mol} ; \lambda_{\max }=592 \mathrm{~nm}$ ) were obtained from a local textile firm in Corlu (Turkey) and used without further purification. The stock solutions of the reactive dyes were prepared in a constant concentration of $1.0 \mathrm{~g} / \mathrm{L}$ and then diluted to appropriate concentrations. Working solutions of the desired concentrations were obtained using successive dilutions. The initial $\mathrm{pH}$ of each solution was adjusted to the required value with concentrated and diluted $\mathrm{HCl}$ and $\mathrm{NaOH}$ solutions before the experiments.

\subsection{Experimental procedure}

Batch sorption experiments were carried out in a $1000 \mathrm{~mL}$ cylindrical jacketed vessel put on an overhead mechanical stirrer (IKA RW 20, Kutay Group, Turkey) which stirred the mixture at various agitation speeds. The mechanical stirrer was used to have well mixed suspension characteristics for the solid particles. Ultrasonic irradiation was chosen as one of the mandatory effects of the removal process and was obtained from a digital ultrasonic cleaner (WiseClean WUC-DH, Wisd, Germany) operating at the frequencies of 5 to $40 \mathrm{kHz}$ and the ultrasonic powers of 16 to $344 \mathrm{~W}$. The vessel was set in ultrasonic cleaner vertically. Total mixture volume was determined as $500 \mathrm{~mL}$ and the experiments were effectuated according to Box-Behnken Design (BBD) considering the previous experiments (Buyukada, 2015).

\subsection{Spectrophotometric analysis}

The solutions were analyzed at predetermined time intervals for the final concentrations of RY145 and RB19 using a UV/vis spectrophotometer (SHIMADZU UV-2100, Biomerieux, France) for the maximum absorbance value. Dye concentration was calculated from a calibration curve. Decolorization efficiency ( $D E, \%)$ at any time was estimated as follows (Buyukada, 2015; Buyukada and Evrendilek, 2016a):

$$
D E=\frac{C_{0}-C_{t}}{C_{0}} \times 100
$$

where $C_{\mathrm{o}}$ and $C_{\mathrm{t}}$ are the initial and measured concentration ( $\mathrm{mg} \mathrm{L}^{-1}$ ) values of the samples at a specified interval during a four-hour reaction, respectively. Dye concentrations ( $C_{R Y 145}$ and $C_{R B 19}, \mathrm{mg} \mathrm{L}^{-1}$ ) after each experiment were calculated using the best-fit calibration plot (absorbance expressed in IU $=0.0189 * C_{R Y 145} ; R^{2}=0.99 ; p<0.001 ; \mathrm{A}=$ $\left.0.0161{ }^{*} C_{\mathrm{RB} 19} ; R^{2}=0.99 ; p<0.001\right)$.

\subsection{Empirical modeling}

120 experiments were performed totally with three replicates considering the Box-Behnken design schedule. Effects of six explanatory variables of adsorbent concentration (AC, $0.5-1.5 \mathrm{~g} \mathrm{~L}^{-1}$ ) (1), initial dye concentration (IDC, $225-375 \mathrm{mg} \mathrm{L}^{-1}$ ) (2), reaction time (RT, $30-120 \mathrm{~min})(3)$, temperature $\left(\mathrm{T}, 25-50^{\circ} \mathrm{C}\right)(4)$, process type (PT, ads and UAA) (5), and dye type (DT, RY145 and $\mathrm{RB} 19)$ on color removal efficiency (DE, \%) were investigated 
experimentally and statistically. Design Expert 9.0.6 (Statease), Minitab 17 (Minitab, Inc., State Collage, PA), and Matlab 2012b (Matworks Inc.) were used to apply RSM and develop MNLR models and ANNs, respectively. The stepwise procedure was used to choose the best-fit MNLR models with the highest goodness-of-fit measured by adjusted coefficient of determination $\left(R^{2}{ }^{2} \mathrm{dj}\right)$, and the highest predictive power measured by coefficient of determination based on leave-one-out cross-validation $\left(R^{2} \mathrm{cv}\right)$. All the predictor variables were treated as the categorical variables in the RMS optimization. The process type of adsorption versus UAA was incorporated in the MNLR models as a categorical variable with adsorption being held as the baseline. Variance inflation factor (VIF) for multicollinearity and Durbin-Watson (DW) statistics for autocorrelation were reported with the best-fit MNLR models (Buyukada, 2017). The parametric test assumptions of normality and constant variance were also tested during the implementation of one-way analysis of variance (ANOVA) and MNLR. Tukey's multiple comparison test following ANOVA at a confidence interval of $95 \%$ was used to detect the significant differences in decolorization efficiency among the explanatory variables.

In this study a single-layer perception (SLP) was used to predict decolorization efficiency based on feedforward Gradient descent with momentum (GDX), adaptive learning rate, and backpropagation algorithm. GDX is not a commonly used model such as Levenberg-Marquardt (LM), and Quasi-Newton (BFG) because of its high iteration time. The SLP network consisted of inputs, and hidden and output layers connected by weights and biases. The input layer included the following four neurons: (1) adsorbent concentration (for all the processes), (2) temperature (for adsorption only) and frequency (for UAA only), (3) reaction time (for all the processes), and (4) initial dye concentration (for adsorption only) and ultrasonic power-dependent weight loss ratio (for UAA only).
Hidden layers were used to solve the complex non-linear functions on the ANNs. The number of neurons in the hidden layers, and training epochs were selected by trial and error. Training and independent validation performances of the ANNs were determined considering root mean square error (RMSE) in Eq. (2) and mean absolute error (MAE) in Eq. (3). An ANN model with the highest $R^{2}$ value and the lowest RMSE and MAE values were selected as the best-fit ANN model according to independent validation data.

$$
\begin{aligned}
& \text { RMSE }=\sqrt{\frac{1}{N}\left(\sum_{i=1}^{N}\left(O_{i}-P_{i}\right)^{2}\right)} \\
& M A E=\frac{1}{N}\left(\sum_{i=1}^{N}\left|O_{i}-P_{i}\right|\right)
\end{aligned}
$$

where $\mathrm{O}_{i}$ and $\mathrm{P}_{i}$ are observed and predicted values, respectively.

\section{Results and discussion}

\subsection{Characterization of $\mathrm{CC}$}

The chemical composition of CC obtained from XRF analysis is presented in Table 1 . Its main components included organic carbon, cellulose, hemicelluloses, and lignin.

The FTIR spectra of CC illustrated in Fig. 1 showed bonded hydroxyl groups (phenolic and alcoholic groups) at $3350 \mathrm{~cm}^{-1}, \mathrm{C}-\mathrm{H}$ vibrations (non-ionic carboxyl groups) at $2750 \mathrm{~cm}^{-1}, \mathrm{C}=\mathrm{O}$ vibrations (carboxyl groups) at $1750 \mathrm{~cm}^{-1}$, $\mathrm{C}=\mathrm{C}$ vibrations (aromatic rings) at $1550 \mathrm{~cm}^{-1}, \mathrm{C}-\mathrm{H}$ vibrations (phenol groups) at $1250 \mathrm{~cm}^{-1}$, and $\mathrm{C}-\mathrm{O}$ vibrations (ether groups) at 1150 and $1070 \mathrm{~cm}^{-1}$.

\begin{tabular}{|c|c|c|}
\hline & Compound & Value (wt \%) \\
\hline \multirow{3}{*}{ As received } & Moisture content & 5.7 \\
\hline & Cellulose & 28.6 \\
\hline & Oil content & 7.3 \\
\hline \multirow{4}{*}{ Dry weight (\%) } & \multicolumn{2}{|c|}{ Proximate analysis } \\
\hline & Ash & 5.2 \\
\hline & Volatile matter & 80.6 \\
\hline & Fixed carbon* & 8.9 \\
\hline \multirow{6}{*}{ Dry weight on ash-free basis (\%) } & \multicolumn{2}{|c|}{ Ultimate analysis } \\
\hline & Organic C & 53.1 \\
\hline & $\mathrm{H}$ & 5.7 \\
\hline & $\mathrm{N}$ & 1.2 \\
\hline & O* & 41.4 \\
\hline & $\mathrm{C} / \mathrm{H}$ & 1.3 \\
\hline
\end{tabular}

Table 1. Chemical composition of dehydrated cottonseed cake (CC)

\footnotetext{
*Estimated by difference
} 


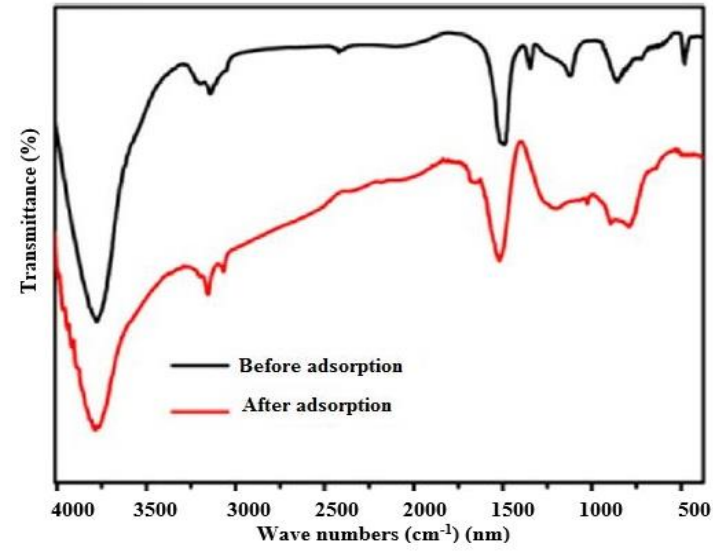

(a)

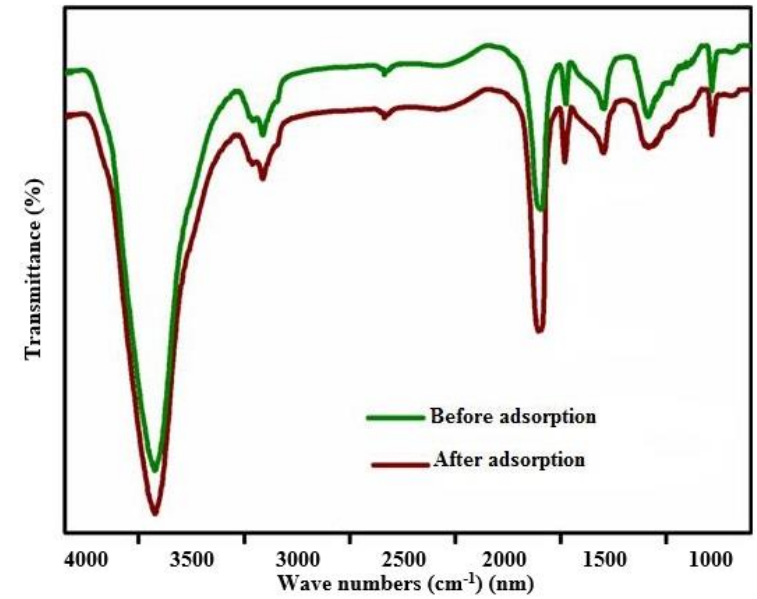

(b)

Figure 1. (a) FTIR spectrum of cottonseed cake (CC) before and after adsorption of RY145, (b) FTIR spectrum of cottonseed cake (CC) before and after adsorption of RB19

Fig. 2 also pointed to hydroxyl and amino groups of CC in a wide vibration range at $3400 \mathrm{~cm}^{-1}$ which decreased significantly with acid hydrolysis of CC. Mean surface area of CC according to the BET analysis were estimated at 26.7 $\mathrm{m}^{2} \mathrm{~g}^{-1}$, while the total pore volume of $\mathrm{CC}$ was determined as $0.253 \mathrm{~cm}^{3} \mathrm{~g}^{-1}$. $\mathrm{N}_{2}$ adsorption isotherm and pore size distribution of CC are shown in Figure 2a. As can be seen from pore size distribution in Figure $2 b, C C$ contained both micropores $(<25 \AA)$ and mesopores $(25 \AA<$ pore width < $400 \AA$ A).

The physicochemical properties of CC are shown in Table 2.

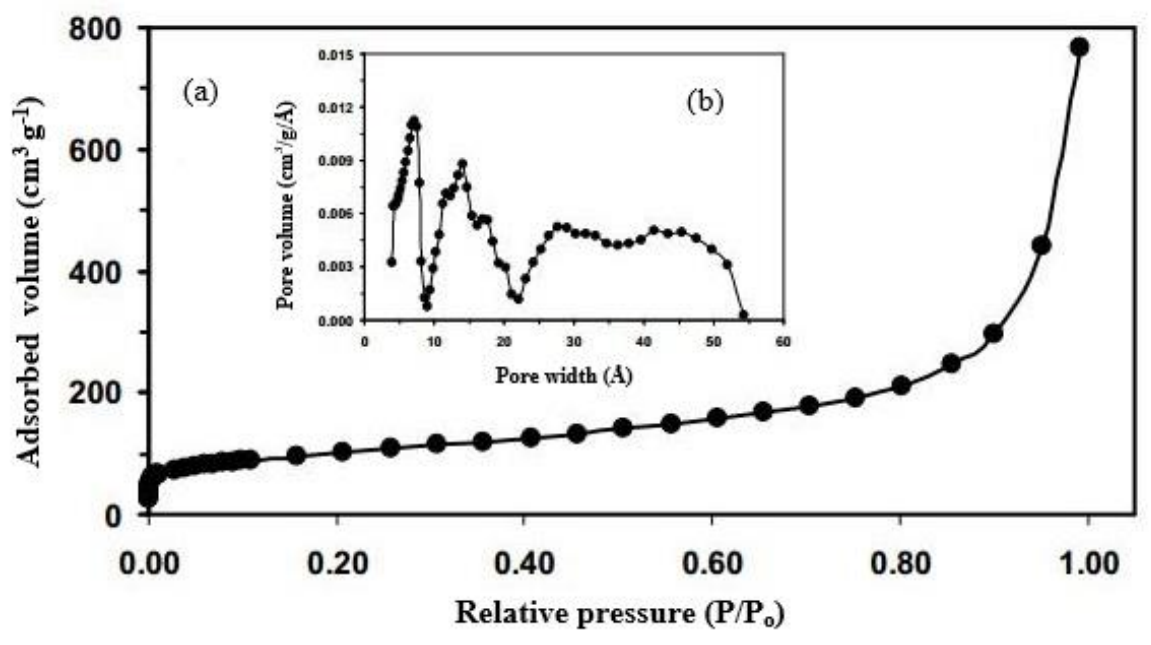

Figure 2. (a) BET surface area and (b) pore size distribution analyses of cottonseed cake (CC)

Table 2. Physicochemical properties of dehydrated cottonseed cake (CC)

\begin{tabular}{cc}
\hline Physicochemical properties & Value \\
\hline Density (picnometric method, $\left.\mathrm{g} \mathrm{cm}^{-1}\right)$ & 1.683 \\
\hline Specific surface area $\left(\mathrm{m}^{2} \mathrm{~g}^{-1}\right)$ & 4.72 \\
\hline Zeta potential $\left(\mathrm{pH}_{\mathrm{zpc}}\right)$ & 5.12 \\
\hline
\end{tabular}

According to the particle size distribution analysis illustrated in Figure 3, the size of CC particles was lower than 50 mesh. In addition, the maximum volume was observed in the particle size of 100 mesh.

\subsection{Linear effects of operating conditions}

A positive correlation was found between reaction time and decolorization efficiency through adsorption ( $r=0.454$, $p=0.011$ ) and UAA ( $r=0.472, p=0.009)$ (Fig. 4). Consistent with our findings, the increased reaction time was also reported to increase decolorization efficiency through 
many wastewater treatment processes (Mall et al., 2006). The extended duration of reaction time was most likely to contribute to a long equilibrium time of the removal process that resulted in increased decolorization efficiency.

The increased initial dye concentration decreased decolorization efficiencies through both adsorption and UAA. This negative correlation between initial dye concentration and decolorization efficiency is illustrated in Figure $4 \mathrm{a}$ and $\mathrm{c}$ for the adsorption process $(r=-0.612 ; p<$ 0.01 ) and in Figure $4 \mathrm{~b}$ and $d$ for the UAA process ( $r=-0.624$; $p<0.001)$. The decreased decolorization efficiency, and the equilibrium time were attributed in the related literature to the increased amount of organic effluent in mixture medium (Mall et al., 2006).

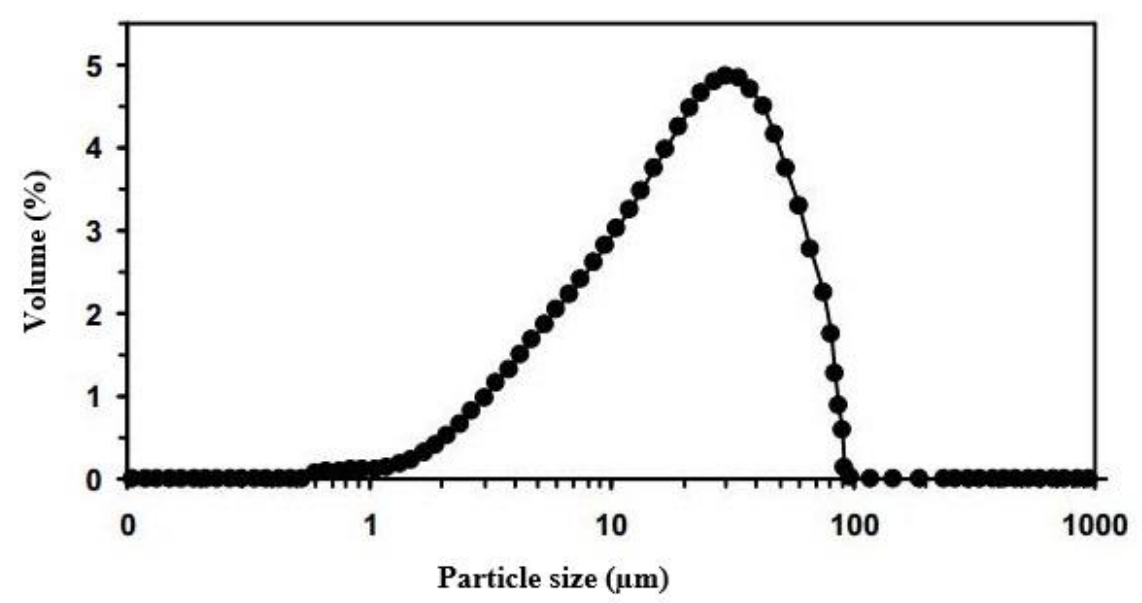

Figure 3. Particle size distribution of cottonseed cake (CC)
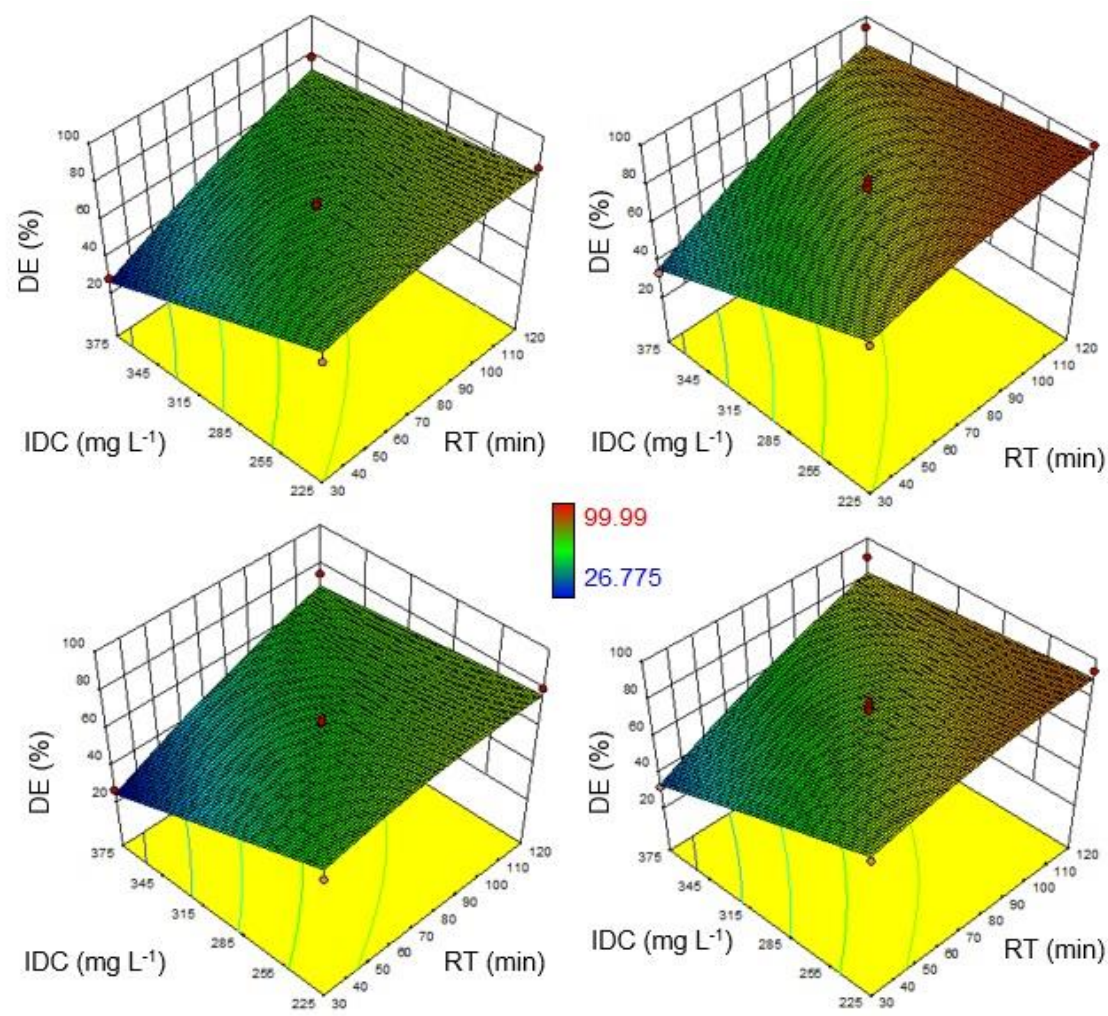

Figure 4. Interaction effects of initial dye concentration (IDC, $\mathrm{mg} \mathrm{L}^{-} 1$ ) by reaction time (RT, $\min$ ) on decolorization efficiency (DE, \%) through (a) adsorption and (b) ultrasound-assisted adsorption (UAA) of RY145 and (c) adsorption and (d) UAA of RB19 under $37.5^{\circ} \mathrm{C}$ and $1.0 \mathrm{~g} \mathrm{~L}^{-1} \mathrm{CC}$ concentration

Temperature was found as the least significant predictor of decolorization efficiency regardless of the process type $(p=0.03)$. A positive correlation was found between temperature and decolorization efficiency through adsorption $(r=0.112 ; p=0.032)$ and UAA $(r=0.121 ; p=$ 
0.028). Likewise, Mall et al. (2006) found increased temperature to lead to increased decolorization efficiency.

Increased quantity of adsorbent in the mixture medium resulted in an increase in decolorization efficiencies through both processes. The strength of the positive correlation between adsorbent concentration and decolorization efficiency gave $r$ values of 0.522 through adsorption ( $p=0.002)$ and 0.573 through UAA $(p=0.001)$. Similar results were also obtained in the study by Mohan et al., (2002).

\subsection{Interaction effects of operating conditions}

According to our ANOVA results, impacts of the following four interaction terms were found significant on the

Table 3. Analysis of variance (ANOVA) results of response surface methodology (RSM) using Box Behnken Design (BBD)

\begin{tabular}{|c|c|c|c|c|c|}
\hline Source & Sum of Squares & df & Mean Square & $F$ Value & $p$ value \\
\hline Model & 31527.40 & 25 & 1322.18 & 81.23 & $<0.0001$ \\
\hline RT & 10852.40 & 1 & 10852.40 & 666.71 & $<0.0001$ \\
\hline IDC & 7936.72 & 1 & 7936.72 & 487.59 & $<0.0001$ \\
\hline $\mathrm{CC}$ & 4565.24 & 1 & 4565.24 & 280.46 & $<0.0001$ \\
\hline $\mathrm{T}$ & 1869.71 & 1 & 1869.71 & 114.86 & $<0.0001$ \\
\hline PT & 4013.82 & 1 & 4013.82 & 246.59 & $<0.0001$ \\
\hline DT & 363.37 & 1 & 363.37 & 22.32 & $<0.0001$ \\
\hline RT*IDC & 1172.18 & 1 & 1172.18 & 72.01 & $<0.0001$ \\
\hline $\mathrm{RT}^{*} \mathrm{CC}$ & 8.22 & 1 & 8.22 & 0.51 & 0.4790 \\
\hline $\mathrm{RT}^{*} \mathrm{~T}$ & 56.65 & 1 & 56.65 & 3.48 & 0.0652 \\
\hline $\mathrm{RT} * \mathrm{PT}$ & 52.58 & 1 & 52.58 & 3.23 & 0.0755 \\
\hline $\mathrm{RT}^{*} \mathrm{DT}$ & 6.51 & 1 & 6.51 & 0.40 & 0.5285 \\
\hline IDC*CC & 267.81 & 1 & 267.81 & 16.45 & 0.0001 \\
\hline IDC*T & 720.62 & 1 & 720.62 & 44.27 & $<0.0001$ \\
\hline IDC*PT & 0.00677 & 1 & 0.00667 & 0.00042 & 0.9838 \\
\hline IDC*DT & 4.76 & 1 & 4.76 & 0.29 & 0.5898 \\
\hline $\mathrm{CC} * \mathrm{~T}$ & 0.17 & 1 & 0.17 & 0.011 & 0.9185 \\
\hline CC*PT & 1.34 & 1 & 1.34 & 0.082 & 0.7748 \\
\hline CC*DT & 2.74 & 1 & 2.74 & 0.17 & 0.6825 \\
\hline T*PT & 1.36 & 1 & 1.36 & 0.084 & 0.7732 \\
\hline$T^{*} \mathrm{DT}$ & 1.12 & 1 & 1.12 & 0.069 & 0.7934 \\
\hline $\mathrm{RT}^{2}$ & 2.41 & 1 & 2.41 & 0.15 & 0.7013 \\
\hline $\mathrm{IDC}^{2}$ & 285.56 & 1 & 285.56 & 17.54 & $<0.0001$ \\
\hline $\mathrm{CC}^{2}$ & 1.90 & 1 & 1.90 & 0.12 & 0.7337 \\
\hline $\mathrm{T}^{2}$ & 10.11 & 1 & 10.11 & 0.62 & 0.4326 \\
\hline Residual & 705.28 & 1 & 705.28 & 43.33 & $<0.0001$ \\
\hline Lack of fit & 3.09 & 94 & 6.28 & 0.36 & 0.5228 \\
\hline Pure error & 1375.02 & 74 & 18.58 & 2.40 & 0.0153 \\
\hline Total & 155.07 & 20 & 7.75 & & \\
\hline
\end{tabular}

CC: Adsorbent concentration ( $\left.L^{-1}\right)$; DE: Decolorization efficiency (\%); df: degrees of freedom; DT: Dye type; IDC: Initial dye concentration ( $\left.m g L^{-1}\right)$; PT: Process type; RT: Reaction time ( $\left.m i n\right)$; and T: Temperature $\left({ }^{\circ} \mathrm{C}\right)$.

\subsection{Effect of ultrasound}

Enhanced adsorption may be due to altered equilibrium time and improved adsorption kinetics. Ultrasonic energy may shift the adsorption equilibrium to a new one (Hamdaoui et al., 2008). Ultrasound may also increase adsorption rate by accelerating mass transfer due to hydro dynamical effects generated by acoustic cavitation (Buyukada and Evrendilek, 2016b). Micro jets and shockwaves produced by cavitation can disrupt the decolorization efficiencies via both adsorption and UAA: (1) initial dye concentration by reaction time $(p<0.001)$, (2) initial dye concentration by temperature $(p<0.001)$, (3) initial dye by adsorbent concentrations $(p=0.001)$, and (4) the quadratic effect of initial dye concentration $(p<$ $0.0001)$. Similar results were obtained in related literature (Sayan and Edecan, 2008; Hamdaoui et al., 2008; Buyukada and Evrendilek, 2016ab). Interaction effects of initial dye concentration by reaction time through adsorption and UAA are illustrated in Figure 4. Our results also showed that all the linear effects of the explanatory variables were significant on the decolorization efficiencies through adsorption and UAA (Table 3). 

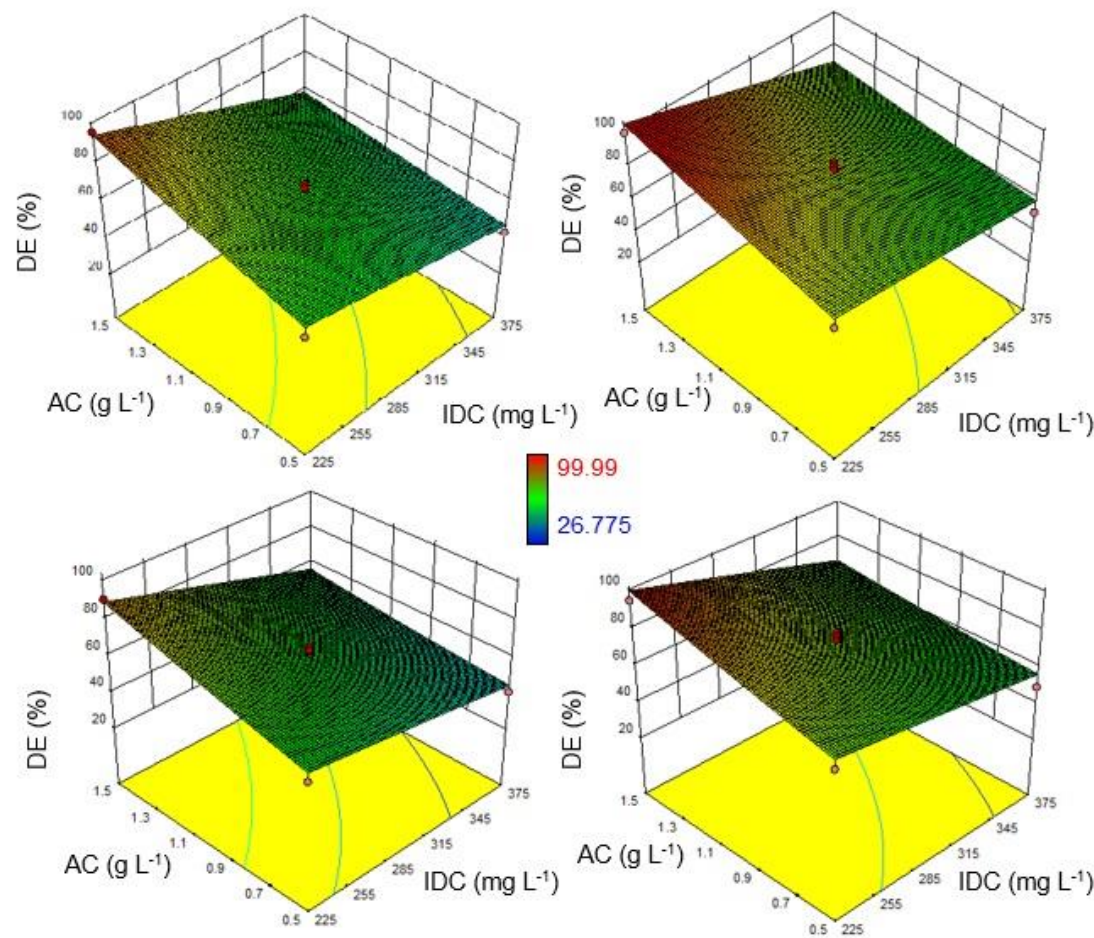

Figure 5. Interaction effects of initial dye concentration (IDC, $\left.m g L^{-1} 1\right)$ by adsorbent concentration $\left(A C, \mathrm{~g} \mathrm{~L}^{-1}\right)$ on decolorization efficiency (DE, \%) through (a) adsorption and (b) ultrasound-assisted adsorption (UAA) of RY145 and (c) adsorption and (d) UAA of RB19 under $37.5^{\circ} \mathrm{C}$ and $75 \mathrm{~min}$ of reaction time
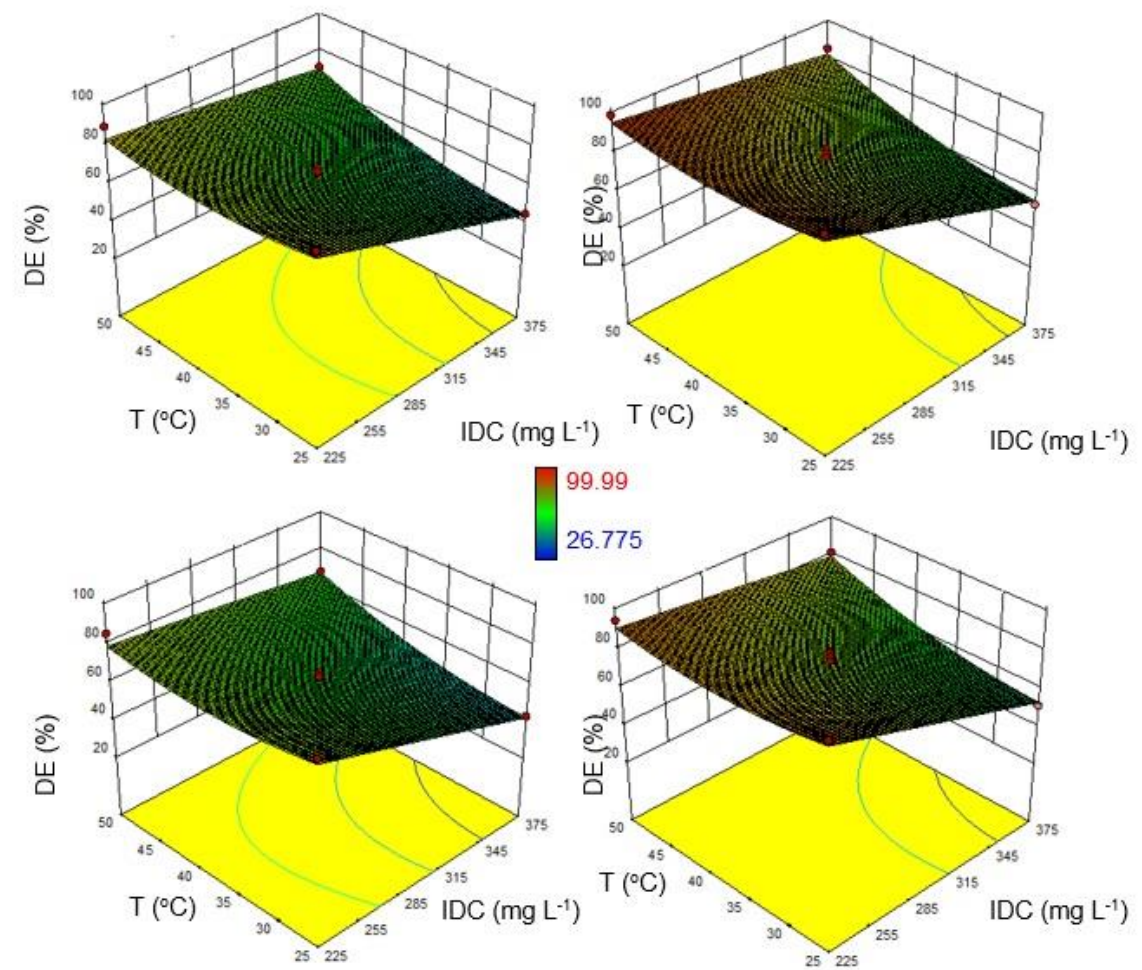

Figure 6. Interaction effects of initial dye concentration (IDC, $m g(-1)$ by temperature $\left(T,{ }^{\circ} \mathrm{C}\right)$ on decolorization efficiency (DE, \%) through (a) adsorption and (b) ultrasound-assisted adsorption (UAA) of RY145 and (c) adsorption and (d) UAA of RB19 under 75 min of reaction time and $1.0 \mathrm{~g} \mathrm{~L}^{-1} \mathrm{CC}$ concentration 


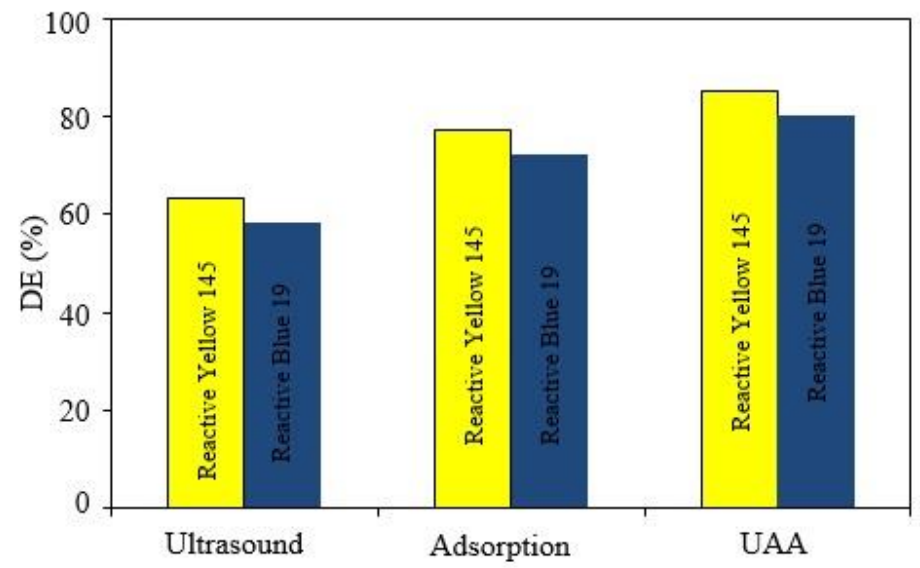

Figure 7. Effects of adsorption, ultrasound, and ultrasound-assisted adsorption (UAA) on decolorization efficiency (DE, \%)

Another statement of significant effect of ultrasound on adsorption efficiency was illustrated in Figure 7.

As a result, both rate and amount of adsorption significantly increased with the presence of the UAA process owing to sonication-enhanced removal of the dyes through the extreme conditions generated by cavitation bubbles. UAA-induced decolorization efficiency of $99.9 \%$ in 5 min can be attributed to the strong convective currents occurring within the reactor. These effects associated with the hydrodynamic phenomena due to cavitation and mechanical stirring are responsible for the perfect mixing of the vessel content. Thus, the vessel used under the ultrasonic irradiation appeared to be a completely stirred tank reactor which was in close agreement with results of similar studies (Hamdaoui et al., 2008; Buyukada and Evrendilek, 2016b).

\subsection{Empirical models}

The best-fit MNLR models of decolorization efficiencies through adsorption and UAA for RY145 and RB19 are presented in Table 4. The most important explanatory variable regardless of the process type was the initial CC concentration given the magnitude of its coefficient. The quadratic and interaction terms of the explanatory variables were significantly influential on the decolorization efficiencies. $R^{2}$ adj of $99.48 \%$ and $R^{2}{ }_{\mathrm{cv}}$ of $97.52 \%$ were found for adsorption of RB19, while $R^{2}$ adj of $98.01 \%$ and $R^{2}$ cv of $96.52 \%$ were found for UAA of RB19. The following two types of ANNs were derived from the experimental data for RY145: single layer perception (SLP) and multilayer perception (MLP). SLPs had an input and only one hidden layer based on tangent sigmoidal, and an output layer based on linear. MLPs had an input and two hidden layers based on sigmoidal and an output layer based on linear.

A total number of 69 ANNs models were built and divided into the three groups: (1) SLPs with 3 to 25 neurons in the hidden layer, (2) MLPs with three neurons in the first hidden layer and 3 to 25 neurons in the second hidden layer, and (3) MLPs with five neurons in the first hidden layer and 3 to 25 neurons in the second hidden layer (Table
5). All the ANNs models were derived using LevenbergMarquardt (TRAINLM) feedforward and backpropagation algorithms. Our results in Table 5 showed that the best-fit ANN45 model had RMSE of 2.04, MAE of 0.012 according to the highest predictive power $\left(R^{2}\right.$ value of $\left.98.57 \%\right)$ for the independent validation. The predictive power of the bestfit MNLR models was $97.79 \%$ for adsorption of RY145 and 96.61\% for UAA of RY145 (Table 4), while that of ANNs ranged from $98.11 \%$ to $99.09 \%$ (Table 5). However, the ANN45 had the highest goodness-of-fit value $\left(R^{2}\right.$ adj $\left.=99.82 \%\right)$, while the best-fit MNLR models had $R^{2}$ adjvalues of $99.52 \%$ for adsorption of RY145 and $98.14 \%$ for UAA of RY145.

\section{6. $R S M$ optimization, validation and ANNs}

The optimal operating conditions for the maximum decolorization efficiency of $99.99 \%$ were determined for both adsorption and UAA consistently thus: 119.99 and $76.98 \mathrm{~min}$ reaction times, initial $\mathrm{MB}$ concentrations of 225.41 and $233.20 \mathrm{mg} \mathrm{L}^{-1}, \mathrm{CC}$ concentrations of 1.41 and $1.37 \mathrm{~g} \mathrm{~L}^{-1}$, and 50 and $35.42{ }^{\circ} \mathrm{C}$, respectively, for RY145 (Table 6). The reaction times of 120 and $79.40 \mathrm{~min}$, initial MB concentrations of 226.50 and $254.29 \mathrm{mg} \mathrm{L}^{-1}, \mathrm{CC}$ concentrations of 1.50 and $1.44 \mathrm{~g} \mathrm{~L}^{-1}$, and 50 and $49.37^{\circ} \mathrm{C}$ were determined as the optimal operating conditions with the maximum decolorization efficiency of $97.84 \%$ and 99.99\% for adsorption and UAA, respectively, for RB19 (Table 6).

Following the development of the best-fit MNLR and ANN models, validation experiments were performed to test the RSM-optimized conditions. Based on the independent validation dataset, ANN45 had the highest $R^{2}$ value of 98.57\% (Table 5). RSM-optimized conditions for the predicted and experimental decolorization efficiencies through adsorption and UAA of RY145 and RB19 are presented in Table 6 . The validation process confirmed that the RSM optimization was successfully applied to the removal of RY145 and RB19 through the adsorption and UAA processes (Table 6). 
Table 4. Multiple non-linear regression (MNLR) models of decolorization efficiency through adsorption and ultrasoundassisted adsorption (UAA)*

\begin{tabular}{|c|c|c|c|c|c|}
\hline \multirow{2}{*}{ Categorical predictor } & \multirow{2}{*}{ Coefficient } & \multicolumn{2}{|c|}{ RY145 } & \multicolumn{2}{|c|}{ RB19 } \\
\hline & & Adsorption & UAA & Adsorption & UAA \\
\hline Constant & 70.15 & 184.2713 & 192.3865 & 181.6553 & 189.2037 \\
\hline RT & 15.04 & -0.0454 & 0.0011 & -0.0618 & -0.0153 \\
\hline IDC & -12.86 & -0.4970 & -0.4973 & -0.4886 & -0.4889 \\
\hline $\mathrm{CC}$ & 9.75 & 49.9592 & 49.2909 & 49.0034 & 48.3352 \\
\hline $\mathrm{T}$ & 6.24 & -3.8492 & -3.8222 & -3.8736 & -3.8467 \\
\hline PT & 5.78 & & & & \\
\hline DT & -1.74 & & & & \\
\hline $\mathrm{RT}^{*} \mathrm{IDC}$ & 8.56 & 0.0024 & 0.0022 & 0.0023 & 0.0021 \\
\hline $\mathrm{RT}^{*} \mathrm{CC}$ & -0.72 & -0.0321 & -0.0319 & -0.0318 & -0.0316 \\
\hline $\mathrm{RT} * \mathrm{~T}$ & -1.88 & -0.0033 & -0.0033 & -0.0033 & -0.0033 \\
\hline $\mathrm{RT} * \mathrm{PT}$ & 1.05 & & & & \\
\hline $\mathrm{RT} * \mathrm{DT}$ & -0.37 & & & & \\
\hline IDC*CC & -4.09 & -0.1090 & -0.1097 & -0.1096 & -0.1093 \\
\hline IDC*T & 6.71 & 0.0072 & 0.0072 & 0.0072 & 0.0072 \\
\hline IDC*PT & -0.012 & & & & \\
\hline IDC*DT & 0.32 & & & & \\
\hline CC*T & 0.10 & 0.0167 & 0.0166 & 0.0169 & 0.0171 \\
\hline CC*PT & -0.17 & & & & \\
\hline CC*DT & -0.24 & & & & \\
\hline $\mathrm{T} * \mathrm{PT}$ & 0.17 & & & & \\
\hline $\mathrm{T}^{*} \mathrm{DT}$ & -0.15 & & & & \\
\hline $\mathrm{RT}^{2}$ & -0.14 & & & & \\
\hline $\mathrm{IDC}^{2}$ & -3.23 & -0.0016 & -0.0015 & -0.0019 & -0.0018 \\
\hline $\mathrm{CC}^{2}$ & -0.26 & -0.00005 & -0.00005 & -0.00005 & -0.00005 \\
\hline $\mathrm{T}^{2}$ & 0.61 & 2.4291 & 2.4289 & 2.4287 & 2.4283 \\
\hline$\left.R_{\text {adj }}^{2} \%\right)$ & 94.40 & 99.52 & 98.14 & 99.48 & 98.01 \\
\hline$R_{\mathrm{cv}}^{2}(\%)$ & 92.35 & 97.79 & 96.61 & 97.52 & 96.52 \\
\hline Adeq. precision & 42.97 & 87.16 & 69.71 & 85.42 & 68.59 \\
\hline SD & 4.03 & 1.04 & 1.68 & 1.15 & 1.76 \\
\hline Mean & 71.02 & 68.76 & 81.12 & 66.24 & 80.35 \\
\hline $\mathrm{CV}$ & 5.68 & 3.42 & 4.28 & 3.69 & 4.52 \\
\hline PRESS & 2644.38 & 4679.36 & 3842.24 & 4371.22 & 3689.16 \\
\hline
\end{tabular}

CC: Adsorbent concentration (g $L^{-1}$ ); DE: Decolorization efficiency (\%); DT: Dye type; IDC: Initial dye concentration (mg $L^{-1}$ ); PT: Process type; RT: Reaction time (min); and T: Temperature $\left({ }^{\circ} \mathrm{C}\right)$. ${ }^{*}$ Binary process was used by which both process type with two levels and dye type with two levels are included

Table 5. Best-fit artificial neural networks (ANNs) of decolorization efficiency (\%) for RY145 as a function of reaction time (min), initial dye concentration $\left(\mathrm{mg} \mathrm{L}^{-1}\right)$, initial adsorbent concentration $\left(\mathrm{g} \mathrm{L}^{-1}\right)$, temperature $\left({ }^{\circ} \mathrm{C}\right)$, process type, and dye type.

\begin{tabular}{|c|c|c|c|c|c|c|c|}
\hline \multirow[b]{2}{*}{ Model } & \multirow[b]{2}{*}{ Structure } & \multirow[b]{2}{*}{ Topology } & \multirow[b]{2}{*}{ RMSE } & \multirow[b]{2}{*}{ MAE } & \multicolumn{3}{|c|}{$R^{2}$ value } \\
\hline & & & & & $\begin{array}{c}\text { Training } \\
\text { (70\%) }\end{array}$ & $\begin{array}{c}\text { Cross-validation } \\
(15 \%)\end{array}$ & $\begin{array}{c}\text { Independent } \\
\text { validation } \\
(15 \%)\end{array}$ \\
\hline ANN6 & $8 * 1$ & SLP & 7.80 & 0.065 & 98.18 & 98.11 & 92.53 \\
\hline ANN45 & $3 * 24 * 1$ & \multirow{2}{*}{ MLP } & 2.04 & 0.012 & 99.67 & 99.03 & 98.57 \\
\hline ANN47 & $5 * 3 * 1$ & & 2.69 & 0.019 & 99.82 & 99.09 & 97.38 \\
\hline
\end{tabular}

MAE: Mean absolute error; MLP: Multilayer perceptron; RMSE: Root mean square error; and SLP: Single layer perceptron

Table 6. Validation of response surface methodology (RSM)-optimized operating conditions for predicted and experimental decolorization efficiencies (DE, \%)

\begin{tabular}{ccccccccc}
\hline DT & RT & IDC & CC & T & PT & Desirability & $\begin{array}{c}\text { DE } \\
\text { (Predicted) }\end{array}$ & $\begin{array}{c}\text { DE } \\
\text { (Experimental) }\end{array}$ \\
\hline RY145 & 119.99 & 225.41 & 1.41 & 50.00 & Adsorption & 0.99 & 99.99 & $98.73 \pm 0.26$ \\
\hline RY145 & 76.98 & 233.20 & 1.37 & 35.42 & UAA & 1 & 99.99 & $99.89 \pm 0.02$ \\
\hline RB19 & 120.00 & 226.50 & 1.50 & 50.00 & Adsorption & 0.97 & 97.84 & $95.22 \pm 0.32$ \\
\hline RB19 & 79.40 & 254.29 & 1.44 & 49.37 & UAA & 1 & 99.99 & $96.66 \pm 0.51$ \\
\hline
\end{tabular}

CC: Adsorbent concentration (g $\mathrm{L}^{-1}$ ); DT: Dye type; IDC: Initial dye concentration (mg $\mathrm{L}^{-1}$ ); PT: Process type; RT: Reaction time (min); and T: Temperature $\left({ }^{\circ} \mathrm{C}\right)$. Desirability ranging from 0 to 1 refers to the confirmation process by which one out of 100 runs of the optimal conditions generated is randomly selected for experiments to be replicated, and results are compared in terms of DE 


\subsection{Comparison of adsorption and UAA with CC to those with different adsorbents}

The UAA treatment with the $\mathrm{CC}$ adsorbent used in this study was compared to the other adsorption and UAA treatments with such adsorbents as poly nanotubes, dehydrated wheat bran carbon, dehydrated peanut hull, and activated carbon under the similar initial Methylene Blue concentrations in terms of decolorization efficiency and adsorbent capacity in Table 7. From Table 7, it can be inferred that UAA with CC appears to be a promising wastewater treatment process. However, it should be noted that operating costs also need to be considered together with decolorization efficiency for comparison. For example, CC is an abundant, and thus, low-cost by-product in Turkey, thus rendering the operating cost of UAA more attractive to the other absorbents.

Table 7. Comparison of adsorption and ultrasound-assisted adsorption (UAA) with dehydrated cottonseed cake (CC) used in this study to those with other adsorbents published in related literature under the similar initial dye (Methylene Blue) (IDC) concentration in terms of decolorization efficiency (DE)

\begin{tabular}{|c|c|c|c|c|}
\hline Decolorization process & IDC (mg L $\left.{ }^{-1}\right)$ & RT (min) & DE (\%) & References \\
\hline Adsorption with PN & 20 & 15 & 95 & Chen et al., (2015) \\
\hline Adsorption with DWBC & 200 & 1800 & 99.84 & Ozer and Dursun, (2007) \\
\hline \multirow{4}{*}{ Adsorption with DPH } & 100 & 1500 & 97.5 & \multirow{4}{*}{ Ozer et al., (2007) } \\
\hline & 150 & 1500 & 81.8 & \\
\hline & 200 & 1500 & 68.2 & \\
\hline & 250 & 1500 & 56.6 & \\
\hline \multirow{2}{*}{ Adsorption with CC } & 50 & 120 & 77.28 & \multirow{4}{*}{ This study } \\
\hline & 250 & 120 & 71.05 & \\
\hline \multirow{2}{*}{ UAA with CC } & 50 & 15 & 87.31 & \\
\hline & 250 & 15 & 80.52 & \\
\hline UAA with AC & 50 & 15 & 99 & Sayan and Edecan, (2008) \\
\hline
\end{tabular}

AC: Activated carbon; DPH: Dehydrated peanut hull; DWBC: Dehydrated wheat bran carbon; and PN: Poly nanotubes

\section{Conclusions}

RSM using BBD was applied to the optimization of decolorization efficiencies for RY145 and RB19 by adsorption and UAA in a batch process. The decolorization efficiencies achieved under RSM-optimized conditions varied between $95.22 \%$ with adsorption for RB19 and 99.99\% with UAA for RB19 and RY145. When validated using the replication experiments, our results confirmed the accuracy of RSM optimization of adsorption and UAA operating conditions. The best-fit MNLR and ANN models identified the significantly linear, quadratic and interaction effects of the predictors. Our results pointed to the better performance of the ANNs than the MNLR models in elucidating changes in the decolorization efficiencies.

\section{Acknowledgements}

The authors would like to thank the Scientific Research Projects Unit of Abant Izzet Baysal University (AIBU) (Projects no: 2015.09.02.920; 2016.09.02.1035; 2016.09.02.1006; 2016.09.02.1007) for financial supports.

\section{Declaration of conflicting interest}

The authors do not have any potential conflicts of interest to declare.

\section{References}

Buyukada M. (2015), Removal of Yellow F3R, Di Maria Brilliant Blue $R$ and Reactive Brilliant Red M-3BE from aqueous Solutions by a rapid and efficient ultrasound-assisted process with a novel biosorbent of cottonseed cake: statistical modeling, kinetic and thermodynamic studies, Arabian Journal for Science and Engineering, 40(8), 2153-2168.

Buyukada M. (2016), Co-combustion of peanut hull and coal blends: artificial neural networks modeling, particle swarm optimization and Monte Carlo simulation, Bioresource Technology, 216, 280-286.

Buyukada M. (2017), Probabilistic uncertainty analysis based on Monte Carlo simulations of co-combustion of hazelnut hull and coal blends: Data driven modeling and response surface optimization, Bioresource Technology, 225, 106-112.

Buyukada M. and Evrendilek F. (2016a), Modeling efficiency of dehydrated sunflower seed cake as a novel biosorbent to remove a toxic azo dye, Chemical Engineering Communications, 203(6), 746-757.

Buyukada M. and Evrendilek F. (2016b), Modeling ultrasoundassisted decolorization efficiency of Reactive Blue 19 and Reactive Yellow 145 from aqueous solutions by cottonseed cake, Fresenius Environmental Bulletin, 25(3), 692-705.

Chen Z., Zhang J., Fu J., Wang M., Wang X., Han R. and Xu Q. (2015), Adsorption of methylene blue onto poly(cyclotriphosphazene-co-4,4'-sulfonyldiphenol) nanotubes: Kinetics, isotherm and thermodynamics analysis, Journal of Hazardous Materials, 273, 263-271.

Dincer A.R., Gunes Y., Karakaya N. and Gunes E. (2007), Coalbased bottom ash (CBBA) waste material as adsorbent for removal of textile dyestuffs from aqueous solution, Journal of Hazardous Materials, 141, 529-535.

Gong R.M., Ding Y., Lie M., Yang C., Liu H.J. and Sun Y.Z. (2005), Utilization of powdered peanut hull as biosorbent for removal of anionic dyes from aqueous solution, Dyes and Pigments, 64, 187-192.

Guo W.Q., Ding J., Cao G.L., Ren N.Q. and Cui F.Y. (2011), Treatability study of using low frequency ultrasonic pretreatment to augment continuous biohydrogen production, International Journal of Hydrogen Energy, 36, 14180-14185.

Hamdaoui O., Chiha M. and Naffrechoux E. (2008), Ultrasoundassisted removal of malachite green from aqueous solution by dead pine needles, Ultrasonics Sonochemistry, 15, 799-807. 
Korkut O., Sayan E., Lacin O. and Bayrak B. (2010), Investigation of adsorption and ultrasound assisted desorption of lead (II) and copper (II) on local bentonite: a modelling study, Desalination, 259, 243-248.

Liu X., Yang Y., Shi X. and Li K. (2015), Fast photocatalytic degradation of methylene blue dye using a low-power diode laser, Journal of Hazardous Materials, 283, 267-275.

Mohan S.V., Rao N.C., Prasad K.K. and Karthikeyan J. (2002), Treatment of simulated Reactive Yellow 22 (Azo) dye effluents using Spirogyra species, Journal of Waste Management, 22, 575-582.

Onat A.T., Gumusdere T.H., Guvenc A., Donmez G. and Mehmetoglu U. (2010), Decolorization of textile azo dyes by ultrasonication and microbial removal, Desalination, 255, 154-158.

Ozer A. and Dursun G. (2007), Removal of methylene blue from aqueous solutions by dehydrated wheat bran carbon, Journal of Hazardous Materials, 146, 262-269.

Ozer D., Dursun G. and Ozer A. (2007), Methylene blue adsorption from aqueous solutions by dehydrated peanut hull, Journal of Hazardous Materials, 144, 171-179.

Ren X.L., Lai X.H., Zhu K.J., Sun Y. and He D.L. (2016), Removal of acid turquoise blue $2 \mathrm{G}$ from aqueous solution by adsorbent derived from sludge and straw: kinetic, isotherm and thermodynamic study, Desalination and Water Treatment, 57(1), 440-448.

Sahinkaya S. (2013), COD and color removal from synthetic textile wastewater by ultrasound assisted electro-Fenton oxidation process, Journal of Industrial Chemistry, 19, 601-605.

Sayan E. and Edecan M.E. (2008), An optimization study using response surface methods on the decolorization of reactive blue 19 from aqueous solution by ultrasound, Ultrasonics Sonochemistry, 15, 530-538.

Tanyildizi M.S. (2011), Modeling of adsorption isotherms and kinetics of reactive dye from aqueous solution by peanut hull, Chemical Engineering Journal, 168, 1234-1240.

Yang S.S., Guo V.Q., Zhou X.J. Meng Z.H., Liu B. and Ren N.Q. (2011), Optimization of operating parameters for sludge process reduction under alternating aerobic/oxygen-limited conditions by response surface methodology, Bioresource Technology, 102, 9843-9851.

Yargic A.S., Yarbay-Sahin R.Z., Ozbay N. and Onal E. (2015), Assessment of toxic copper (II) biosorption from aqueous solution by chemically-treated tomato waste, Journal of Cleaner Production, 88, 152-159.

Zhou X.J., Guo W.Q., Yang, S.S. and Ren N.Q. (2013), Ultrasonicassisted ozone oxidation process of triphenyl methane dye degradation: evidence for the promotion effects of ultrasonic on malachite green decolorization and degradation mechanism, Bioresource Technology, 128, 827-830. 